\title{
The role of oxidative stress in apoptosis induced by the histone deacetylase inhibitor suberoylanilide hydroxamic acid in human colon adenocarcinoma HT-29 cells
}

\author{
PATRIZIA PORTANOVA, TIZIANA RUSSO, ORNELLA PELLERITO, GIUSEPPE CALVARUSO, \\ MICHELA GIULIANO, RENZA VENTO and GIOVANNI TESORIERE
}

Dipartimento di Scienze Biochimiche, Università degli Studi di Palermo, Via del Vespro 129, 90127 Palermo, Italy

Received December 31, 2007; Accepted February 20, 2008

DOI: 10.3892/ijo_00000012

\begin{abstract}
Histone deacetylase inhibitors (HDACIs) activate genes that promote cell cycle arrest and apoptosis in a number of tumor cells. This study showed that suberoylanilide hydroxamic acid (SAHA), a potent and commonly used HDACI, induced apoptosis in human colon adenocarcinoma HT-29 cells in a time- and dose-dependent manner. This effect was accompanied by the induction of oxidative stress, dissipation of mitochondrial transmembrane potential and activation of executioner caspases. Moreover, SAHA increased the levels of phosphorylated active forms of p38 and JNK. The addition of either the antioxidant N-acetylcysteine or the specific inhibitor of NADPH oxidase diphenylene iodonium chloride reduced the cytotoxic effects of SAHA in HT-29 cells, suggesting that the induction of oxidative stress represents a crucial event in the apoptotic mechanism. In addition, SAHA up-regulated the death receptor DR5, inducing the activation of caspase- 8 with the consequent cleavage of Bid. Furthermore, SAHA downregulated $\mathrm{FLIP}_{\mathrm{L}}$ and Akt, two proteins which exert an inhibitory role in apoptosis.
\end{abstract}

\section{Introduction}

Reversible histone acetylation/deacetylation is one of the key mechanisms involved in the epigenetic control of gene expression (1). Acetylation depends on histone acetyltransferases, which acetylate lysine residues at the $\mathrm{N}$-terminal tails of core histones, neutralizing their positive charges. Deacetylation is catalyzed by histone deacetylases (HDACs), a family of different enzymes, which remove acetyl groups causing DNA to wrap more tightly around the histone octamer. This event is associated with a relatively compact and

Correspondence to: Professor Giovanni Tesoriere, Dipartimento di Scienze Biochimiche, Università degli Studi di Palermo, Via del Vespro 129, 90127 Palermo, Italy

E-mail: gtesor@unipa.it

Key words: suberoylanilide hydroxamic acid, apoptosis, oxidative stress, colon adenocarcinoma inaccessible chromatin state, which generally correlates with lower gene transcription.

The histone deacetylase inhibitors (HDACIs) act by promoting the acetylated forms of core histones, weakening the histone-DNA interactions and inducing the relaxation of the chromatin structure, followed by transcriptional activation of genes involved in the control of cell proliferation, differentiation and apoptosis (2). Since the anti-proliferative and pro-apoptotic effects are more pronounced in tumor cells than in normal cells, HDACIs have recently emerged as promising chemotherapeutic agents $(3,4)$.

HDACIs belong to a heterogeneous class of compounds that includes derivatives of short chain fatty acids, hydroxamic acids, cyclic tetrapeptides and benzamides (5).

Hydroxamic acids have attracted the attention of researchers because of their high antiproliferative properties in many tumor types in vitro and in vivo. Specifically, suberoylanilide hydroxamic acid (SAHA) has been shown to inhibit the growth of transformed human cells, including erythroleukemia and lymphoma cells (6), as well as cultured cell lines obtained from different solid cancers $(7,8)$. In addition, a clinical investigation demonstrated that SAHA exhibits a high therapeutic potential in the treatment of various malignancies at doses that were well-tolerated by patients (9).

Another notable property of SAHA is its ability to exert antitumor effects in a synergistic manner with various compounds such as TRAIL $(10,11)$ and anticancer drugs, such as topoisomerase $(12,13)$ and proteasome inhibitors (14). Recently, we demonstrated that in human hepatoma cells SAHA strongly induces apoptosis showing also a clear synergistic effect with the proteasome inhibitor bortezomib (15). In contrast, SAHA, alone or in combination with bortezomib, was found to be ineffective in inducing apoptosis in primary human hepatocytes (15).

The biochemical mechanism through which SAHA induces apoptosis is under active investigation. It has been shown that SAHA alters the expression of a large number of genes which can be involved in apoptosis or cell survival mechanisms (16).

Colorectal carcinoma represents one of the main causes of cancer-related death in the world. Currently available protocols of treatment include the antimetabolite 5-fluorouracil, topoisomerase inhibitors and platin derivatives $(17,18)$. 
However, this tumor appears to develop resistance to chemotherapy owing to a variety of survival mechanisms, including the enhanced efflux of drugs and alterations in drug metabolism (19).

Additionally, HDACIs have been considered as potential chemotherapeutic agents against colorectal carcinoma based on the observation that high dietary fiber intake has been associated with a reduced risk for this type of neoplasia. This effect is ascribed to n-butyrate, a histone deacetylase inhibitor, which is produced in the gastrointestinal tract $(20,21)$. Furthermore, histone acetylation has been associated with enhanced radiocytotoxicity in certain colorectal carcinoma cell lines (22).

In our study, we analyzed the cytotoxic activity of SAHA in the colon cancer HT-29 cell line. We provide evidence that SAHA is particularly efficacious in inducing apoptosis in HT-29 cells through a mechanism involving the production of reactive oxygen species (ROS), dissipation of mitochondrial transmembrane potential and the activation of executioner caspases.

\section{Materials and methods}

Chemicals and reagents. SAHA was obtained from Italfarmaco S.p.a. (Milan, Italy). Benzyloxy carbonyl-ValAla-Asp-fluoromethylketone (z-VAD) was from Promega (Italy). N-acetylcysteine (NAC) and diphenylene iodonium chloride (DPI) were supplied by Sigma (St. Louis, MO). Each antibody used was purchased from Cell Signalling (Beverly, MA, USA), except Bid antibody (Santa Cruz Bio, Santa Cruz, CA, USA) and pro-caspase-6 antibody (Sigma). Stock solutions of SAHA were prepared in DMSO and opportunely diluted in the culture medium. The final concentration of DMSO never exceeded $0.04 \%$.

Cell culture conditions. Human colon adenocarcinoma HT-29 cells were grown as monolayers in RPMI-1640 medium, supplemented with $10 \%(\mathrm{v} / \mathrm{v})$ heat-inactivated foetal calf serum (FCS) and $2.0 \mathrm{mM}$ L-glutamine. The cells were maintained at $37^{\circ} \mathrm{C}$ in a humidified atmosphere containing $5 \% \mathrm{CO}_{2}$. For the experiments, cells were seeded at $60-70 \%$ confluence. After plating, cells were allowed to adhere overnight and then treated with the compounds.

Cell cycle analysis. The cell cycle phase distribution was evaluated through flow cytometric analysis. After exposure to the drugs, cells were harvested by trypsinization and incubated for $2-3 \mathrm{~h}$ at $4{ }^{\circ} \mathrm{C}$ in a hypotonic solution containing $50 \mu \mathrm{g} / \mathrm{ml}$ propidium iodide, $0.1 \%$ sodium citrate, $0.01 \%$ Nonidet P-40 and $10 \mu \mathrm{g} / \mathrm{ml}$ RNase A. The cell cycle profiles were analysed by Epics XL flow cytometer (Beckman Coulter) using Expo32 software. Apoptosis was determined by evaluating the percentage of events accumulated in the sub-G0/G1 position, according to Darzynkiewicz et al (23).

Measurement of ROS production. ROS production was measured by using 2',7'-dichlorofluorescindiacetate $\left(\mathrm{H}_{2} \mathrm{DCFDA}\right.$, Molecular Probes, Eugene, $\left.\mathrm{OR}\right)$, an indicator for ROS which is converted into a fluorescent compound after the removal of the acetate groups by intracellular esterases and oxidation by ROS.

After treatment, the cells were gently washed once with warm buffer $\mathrm{HBSS} / \mathrm{Ca} / \mathrm{Mg}$ and incubated with $5 \mu \mathrm{M}$ $\mathrm{H}_{2}$ DCFDA dye at $37^{\circ} \mathrm{C}$ for $30 \mathrm{~min}$. The cells were trypsinized, re-suspended in a buffer and analysed by flow cytometry at the excitation and emission setting of 488 and $525 \mathrm{~nm}$, respectively, using Expo32 software. The percentage of cells showing a higher fluorescence, which reflects ROS production, was determined by comparison with untreated controls.

Measurement of mitochondrial transmembrane potential $\left(\Delta \psi_{m}\right)$. Mitochondrial transmembrane potential was measured by using 3,3-dihexyloxacarbocyanine $\left(\mathrm{DiOC}_{6}\right.$, Molecular Probes, Eugene, OR), a fluorochrome which exclusively emits within the spectrum of green light and accumulates in the mitochondrial matrix under the influence of $\Delta \psi_{\mathrm{m}}$.

HT-29 cells were harvested by trypsinization, treated with $40 \mathrm{nM} \mathrm{DiOC} 6$ for $20 \mathrm{~min}$ at $37^{\circ} \mathrm{C}$, washed with phosphatebuffered saline and analysed by flow cytometry using the excitation and emission setting of 488 and $525 \mathrm{~nm}$, respectively. The percentage of cells showing lower fluorescence, reflecting the loss of $\Delta \psi_{\mathrm{m}}$, was determined by comparison with untreated controls.

Western blot analysis. Whole cell extracts were prepared by dissolving the cells in lysis buffer (1\% NP-40, $0.5 \%$ sodium deoxycholate and $0.1 \%$ SDS in PBS, $\mathrm{pH} 7.4$ ) for $30 \mathrm{~min}$ at $4^{\circ} \mathrm{C}$ in the presence of a mix of protease inhibitors $(25 \mu \mathrm{g} / \mathrm{ml}$ aprotinin, $1 \mathrm{mM}$ phenylmethylsulfonyl fluoride, $10 \mathrm{mM}$ sodium ortovanadate, $10 \mathrm{mM} \mathrm{NaF}, 25 \mu \mathrm{g} / \mathrm{ml}$ leupeptin, $0.2 \mathrm{mM}$ sodium pyrophosphate). Cells were then sonicated three times for $10 \mathrm{sec}$ and the lysates centrifuged at $15,000 \mathrm{x} \mathrm{g}$ for $20 \mathrm{~min}$ at $4^{\circ} \mathrm{C}$. Equal amounts of protein samples $(60 \mu \mathrm{g} / \mathrm{lane})$ were subjected to SDS-polyacrylamide gel electrophoresis and then transferred to a nitrocellulose membrane for the detection with specific antibodies. Immunoblots were detected as previously reported (24). The correct protein loading was verified by means of Ponceau red staining and actin immunodetection. Bands were quantified by densitometric analysis using SMX Image software.

\section{Results}

The effects of the histone deacetylase inhibitor SAHA on $H T-29$ cell viability. Fig. 1 shows the effects of SAHA on the cell cycle distribution of HT-29 cells. Experiments were performed by means of flow cytometric analysis after staining of DNA with propidium iodide. The percentage of cells with subdiploid DNA confined to the sub-G0/G1 phase of the cell cycle was assumed as apoptosis index. Treatment with SAHA increased this percentage in a dose-dependent manner, so that at $36 \mathrm{~h}$ the percentage of cells in the sub-G0/G1 phase reached $92.5 \%$ with $5 \mu \mathrm{M}$ SAHA (Fig. 1A).

In time-dependent experiments, we demonstrated that in the first phase of treatment (4-8 h) $5 \mu \mathrm{M}$ SAHA induced an accumulation of HT-29 cells in the G2/M phase of the cell cycle. For longer periods, it was observed as a progressive increase in the percentage of cells confined to the sub-G0/G1 phase, which reached $44 \%$ at $24 \mathrm{~h}$ and $92 \%$ at $36 \mathrm{~h}$ of 
A
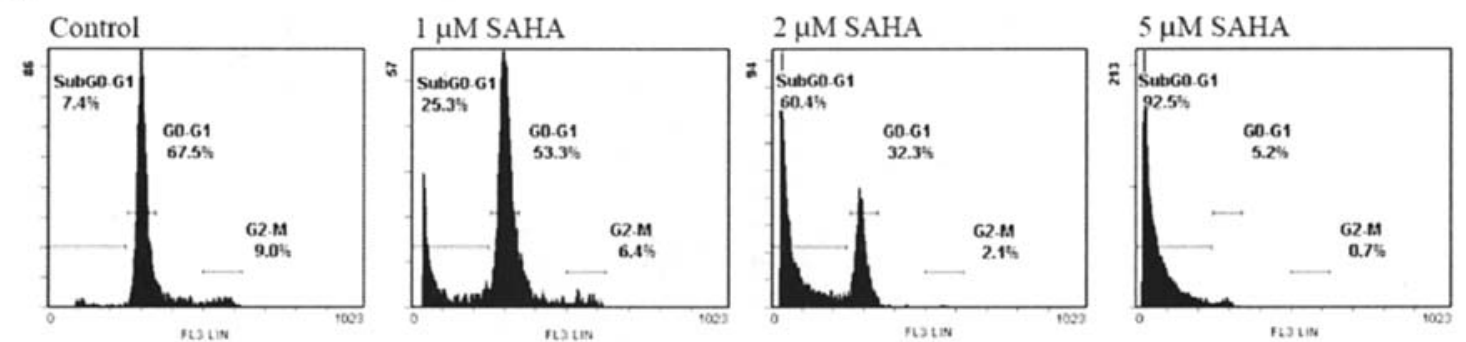

B

\begin{tabular}{lccc}
\hline & $\%$ Sub-G0/G1 & $\% \mathrm{G} 0 / \mathrm{G} 1$ & $\% \mathrm{G} 2 / \mathrm{M}$ \\
\hline Control & $5.1 \pm 0.4$ & $66.1 \pm 4.6$ & $8.4 \pm 0.6$ \\
SAHA 4 h & $6.4 \pm 0.4$ & $40.2 \pm 2.8$ & $35.6 \pm 2.5$ \\
SAHA 8 h & $12.1 \pm 0.8$ & $30.5 \pm 2.1$ & $40.6 \pm 2.8$ \\
SAHA 16 h & $25.8 \pm 1.8$ & $26.9 \pm 1.9$ & $35.2 \pm 2.5$ \\
SAHA 24 h & $44.3 \pm 3.1$ & $17.9 \pm 1.2$ & $31.8 \pm 2.2$ \\
SAHA 36 h & $92.5 \pm 6.5$ & $5.3 \pm 0.4$ & $0.6 \pm 0.04$ \\
SAHA + z-VAD 36 h & $42.3 \pm 2.9$ & $28.6 \pm 2.0$ & $18.4 \pm 1.3$ \\
\hline
\end{tabular}

Figure 1. The effects of SAHA on cell cycle distribution of HT-29 cells. Cells were incubated for $36 \mathrm{~h}$ (A) with the indicated doses of SAHA or for various times (B) with $5 \mu \mathrm{M}$ of SAHA. After staining with propidium iodide, the percentage of cells confined in the different phases of the cell cycle was quantified by a flow cytometric analysis. The results are representative of four independent experiments \pm SE.
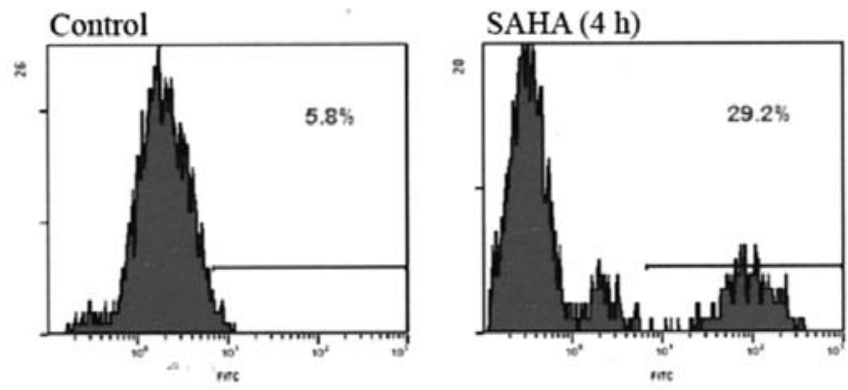

SAHA $(8 \mathrm{~h})$
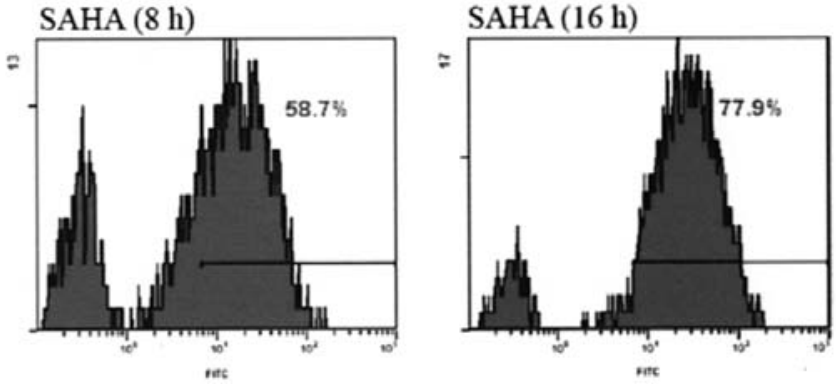

Figure 2. SAHA induced ROS production in HT-29 cells. Cells were treated for different times (4-16 h) with $5 \mu \mathrm{M}$ of SAHA. The quantification of ROS was performed by flow cytometry with $\mathrm{H}_{2}$ DCFDA, as reported in Materials and methods. Untreated cells were assumed as the control. Data are representative of four separate experiments with similar results.

treatment. The addition of $100 \mu \mathrm{M} \mathrm{z}-\mathrm{VAD}$, a general caspase inhibitor, partially counteracted the effect induced by SAHA at $36 \mathrm{~h}$ of treatment, suggesting that caspase activities are involved in the cytotoxic effects induced by the drug (Fig. 1B).
The induction of oxidative stress and mitochondrial damage in SAHA-treated HT-29 cells. Previous studies have shown that HDACIs induce oxidative stress in transformed cells (25). In order to evaluate the involvement of oxidative stress in apoptosis induced by SAHA in HT-29 cells, we studied the effect of the drug on the production of ROS by using $\mathrm{H}_{2}$ DCFDA, a nonfluorescent lipophilic probe commonly employed to detect the cellular production of ROS. The removal of acetate groups by intracellular esterases and the ROS-dependent oxidation converts $\mathrm{H}_{2}$ DCFDA in a fluorescent compound detectable by flow cytometric analysis as a shift of the fluorescence histogram to the right. In HT-29 cells, treatment with $5 \mu \mathrm{M}$ of SAHA caused a time-dependent increase in ROS-related fluorescence (Fig. 2). The effect reached the maximum after $16 \mathrm{~h}$ and thereafter, ROS production decreased (not shown).

It is well known that a possible consequence of ROS production is the loss of mitochondrial inner membrane potential $\left(\Delta \psi_{\mathrm{m}}\right)(26)$. Therefore, we investigated whether SAHA is capable of inducing dissipation of $\Delta \psi_{\mathrm{m}}$ in HT-29 cells using a cytofluorimetric analysis which employs $\mathrm{DiOC}_{6}$, a mitochondria-specific and voltage-dependent dye. The results indicated that $5 \mu \mathrm{M}$ of SAHA induced a dissipation of $\Delta \psi_{\mathrm{m}}$, as indicated by the increase in the percentage of cells with lower fluorescence. The effect started at $8 \mathrm{~h}$ and after $36 \mathrm{~h}$ $\sim 80 \%$ of the HT-29 cells were depolarized (Fig. 3). The addition of $100 \mu \mathrm{M} \mathrm{z}$-VAD markedly reduced the loss of $\Delta \psi_{\mathrm{m}}$ induced by SAHA after $36 \mathrm{~h}$ of treatment.

In addition, we observed activation of caspase- 9 as demonstrated by the reduction of the band corresponding to its 


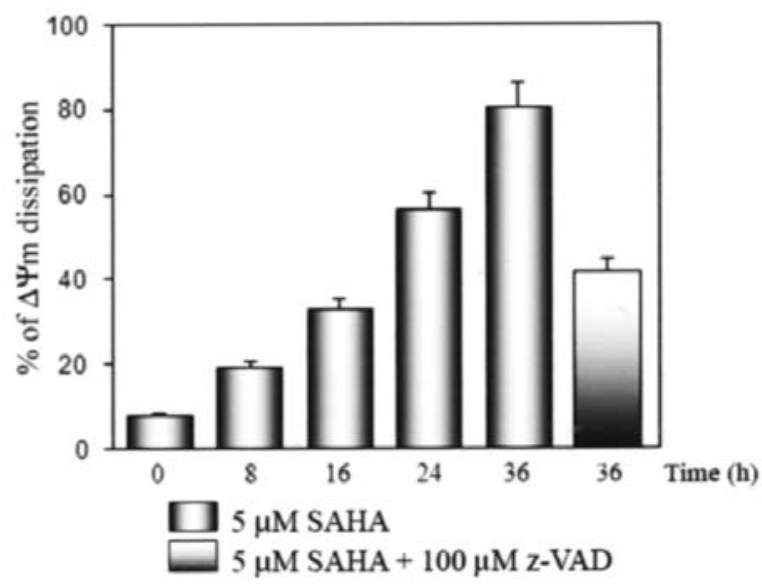

Figure 3. The effect of SAHA on mitochondrial transmembrane potential in HT-29 cells. Cells were treated for different times $(8-36 \mathrm{~h})$ with $5 \mu \mathrm{M}$ of SAHA. Quantification of $\Delta \psi_{\mathrm{m}}$ was performed by flow cytometry with the lipophilic dye $\mathrm{DiOC}_{6}$, as reported in Materials and methods. Untreated cells were assumed as the control. The data are representative of three separate experiments with similar results.

inactive form and the appearance of the cleavage products of 37 and $35 \mathrm{kDa}$ corresponding to its intermediate and active forms, respectively. This cleavage was evident after $16 \mathrm{~h}$ of treatment and at $24 \mathrm{~h}$ the intensity of the band at $35 \mathrm{kDa}$ was $\sim$ three-fold the control value (Fig. 4). Such an effect seems to be correlated with the loss of $\Delta \psi_{\mathrm{m}}$ induced by SAHA.

Activation of the apoptotic pathway in SAHA-treated HT-29 cells. To further investigate the putative molecular mechanism of the apoptotic activity of SAHA, we assessed the expression of a number of pro- and anti-apoptotic factors in HT-29 cells exposed to the drug.

Some experiments were performed in order to evaluate the effect of SAHA on death receptors and their ligands. Western blot analysis showed that SAHA did not modify the expression of the FAS receptor and its ligand (not shown) while it induced up-regulation of DR5, another membrane death receptor, which is associated with the TNF-related apoptosis-inducing ligand (TRAIL). Fig. 4 shows that this effect was already evident after $8 \mathrm{~h}$ of treatment, then increased with time reaching at $24 \mathrm{~h}$ a level about two-fold higher than the control value. In addition, the effect was dependent on SAHA concentration (not shown).

Then, we analysed the effect of SAHA on death receptorrelated caspase- 8 and its specific inhibitor FLIP. Two major FLIP splicing variants are present in cells: a short, $26 \mathrm{kDa}$ protein $\left(\mathrm{FLIP}_{\mathrm{S}}\right)$ and a longer, $55 \mathrm{kDa}$ form $\left(\mathrm{FLIP}_{\mathrm{L}}\right)$, which shows a high homology to the prodomain of caspase-8 (27). Treatment with $5 \mu \mathrm{M}$ of SAHA induced in HT-29 cells the processing of pro-caspase- 8 with the appearance of the cleavage product of $43 / 41 \mathrm{kDa}$ corresponding to its active form. The effect was already evident after $16 \mathrm{~h}$ of treatment and increased at $24 \mathrm{~h}$. Moreover, Western blot analysis showed a progressive decrease in the level of FLIP $_{\mathrm{L}}$ with almost the disappearance of the corresponding band after $24 \mathrm{~h}$ of treatment (Fig. 4). Appreciable variations in the levels of FLIP $_{\mathrm{S}}$ were not observed.

In addition, a marked decrease in the native Bid protein (22 kDa) was observed in SAHA-treated HT-29 cells with the appearance of a $15 \mathrm{kDa}$ band corresponding to its truncated active form (tBid). This effect can be considered as a consequence of caspase- 8 activation.
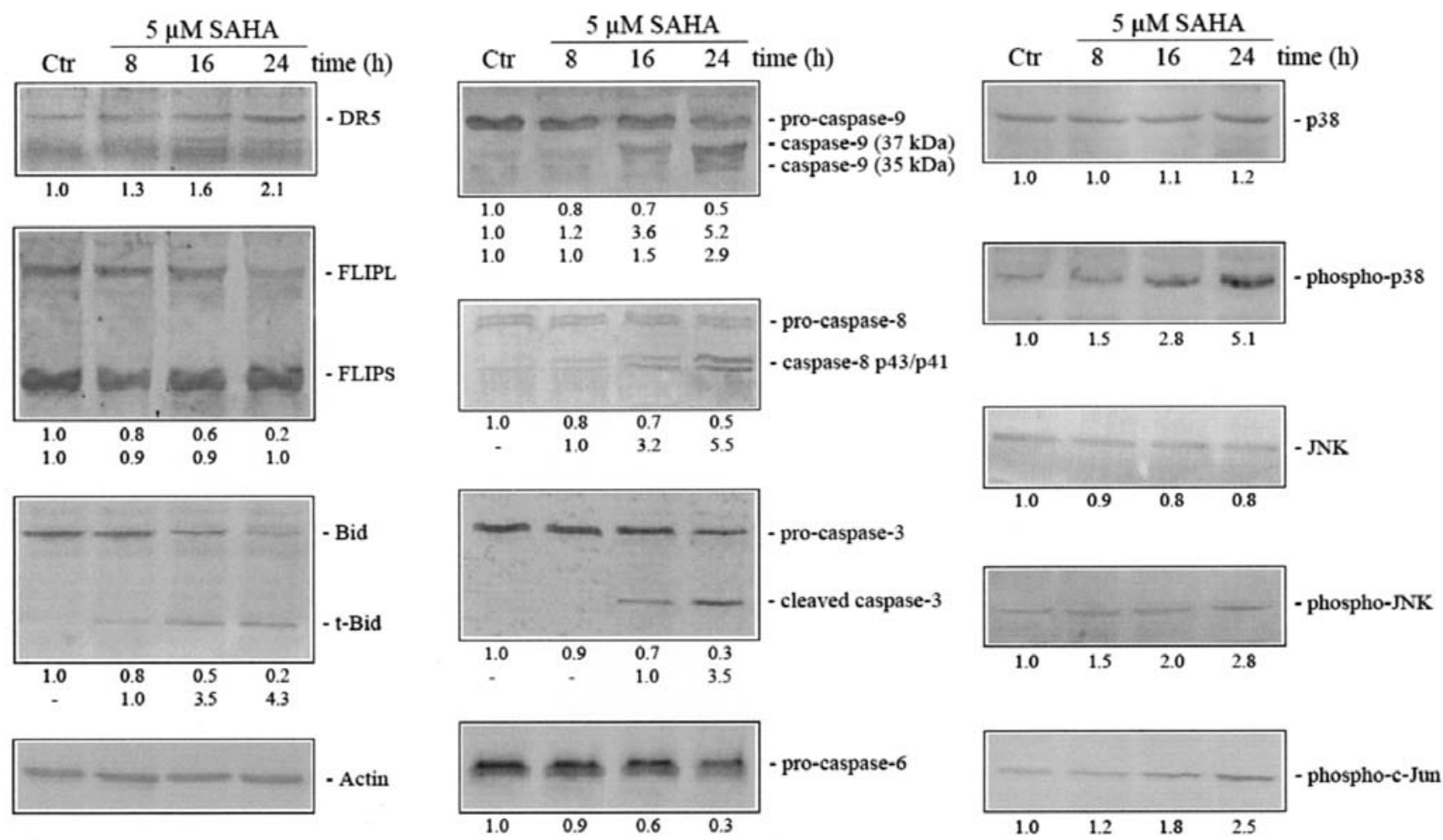

Figure 4. The effect of SAHA on apoptosis regulatory factors in HT-29 cells. Cells were treated for different times (8-24 h) with $5 \mu$ M of SAHA. Then, cell lysates were analysed by SDS-PAGE and Western blotting as indicated. Untreated cells were assumed as the control. The data are representative of four separate experiments with similar results. 
A

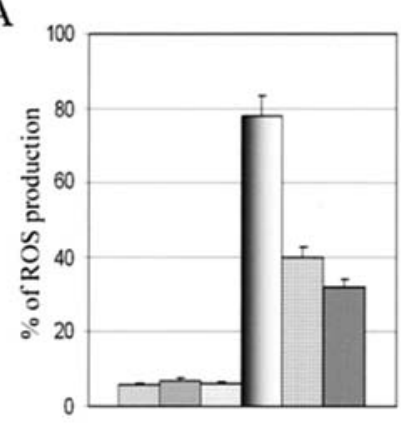

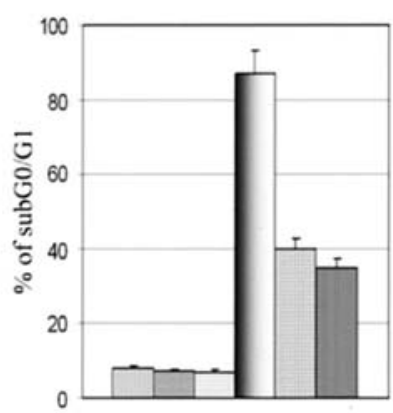

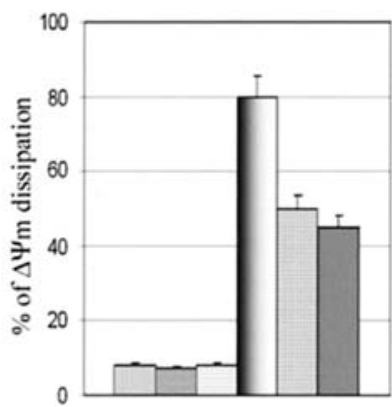

Control

$10 \mathrm{mMNAC}$

$2.5 \mu \mathrm{M}$ DPI
$5 \mu \mathrm{M} \mathrm{SAHA}$

๑ $5 \mu \mathrm{M} \mathrm{SAHA}+10 \mathrm{mM} \mathrm{NAC}$

$\square 5 \mu \mathrm{M} \mathrm{SAHA}+2.5 \mu \mathrm{M}$ DPI
B

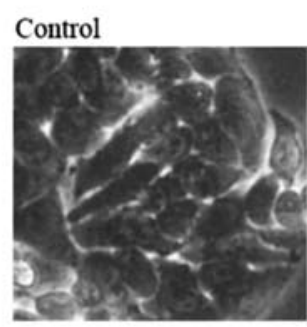

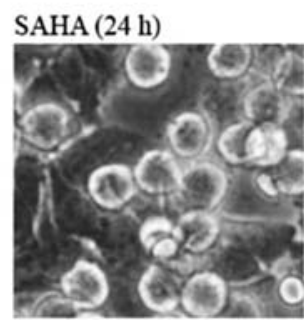

Figure 5. NAC and DPI prevented the effect of SAHA on ROS production, apoptosis and $\Delta \psi_{\mathrm{m}}$ dissipation. (A) Cells were treated with $5 \mu \mathrm{M}$ of SAHA in the presence of $10 \mathrm{mM}$ NAC or $2.5 \mu \mathrm{M}$ DPI. The effect on ROS production was evaluated at $16 \mathrm{~h}$ of treatment, while those on sub-G0/G1 accumulation and transmembrane potential dissipation at $36 \mathrm{~h}$ of treatment. (B) Morphological analysis of HT-29 cells treated for $24 \mathrm{~h}$ with $5 \mu \mathrm{M}$ of SAHA in the presence or absence of $2.5 \mu \mathrm{M}$ DPI. Data are representative of three separate experiments with similar results.

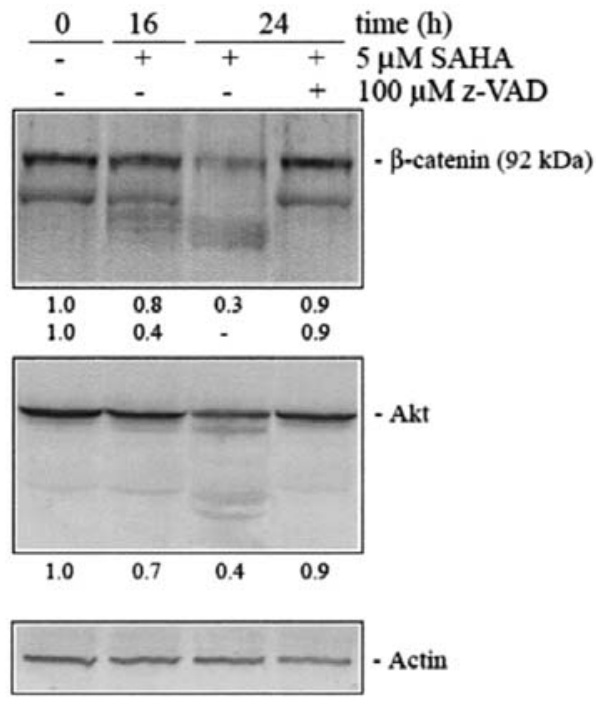

Figure 6. The effect of SAHA on the levels of B-catenin and Akt. Cells were treated for 16 and $24 \mathrm{~h}$ with $5 \mu \mathrm{M}$ of SAHA in the presence or absence of $100 \mu \mathrm{M}$ z-VAD. Then, cell lysates were analysed by SDS-PAGE and Western blotting. Untreated cells were assumed as the control. The data are representative of four separate experiments with similar results.

The activation of extrinsic and mitochondrial pathways led to the cleavage of executioner proteases. Clear reductions in the levels of pro-caspase- 3 and pro-caspase- 6 were observed after SAHA treatment and after $24 \mathrm{~h}$ the intensities of the corresponding bands were $\sim 30 \%$ of the respective control values. Moreover, the specific antibody for caspase- 3 also evidenced the appearance of its cleaved active form of $17 \mathrm{kDa}$ (Fig. 4).

The effect of $N$-acetylcysteine and diphenyleneiodonium on ROS production, DNA fragmentation and mitochondrial membrane potential dissipation in SAHA-treated HT-29 cells. To study the role of oxidative stress in SAHA-induced cell death, we analysed whether the antioxidant NAC or the inhibitor of NADPH oxidase DPI are capable of modifying the effects induced by SAHA on HT-29 cells. Fig. 5A shows that the addition of $10 \mathrm{mM}$ NAC to $5 \mu \mathrm{M}$ of SAHA reduced the percentage of cells with ROS-related fluorescence by $\sim 50 \%$. In the same conditions, it was observed that the percentage of treated cells confined to the sub-G0/G1 phase of the cell cycle decreased by $\sim 55 \%$. In concomitance, SAHA-induced dissipation of the mitochondrial inner membrane potential was reduced by the addition of NAC (Fig. 5A).

The addition of $2.5 \mu \mathrm{M}$ DPI significantly diminished ROS generation in SAHA-treated cells, as well as the percentage of cells confined to the sub-G0/G1 phase of the cell cycle and the dissipation of mitochondrial transmembrane potential (Fig. 5A). Moreover, as demonstrated by microscopic analysis (Fig. 5B), DPI almost completely reverted the morphological changes induced by $24 \mathrm{~h}$ of treatment with SAHA in HT-29 cells, consisting in the isolation and detaching from culture substrate of cells with rounded profiles. These results strongly suggest the involvement of NADPH oxidase in SAHA-induced ROS production and apoptosis. 
The activation of the p38/JNK pathway in SAHA-treated cells. It was reported that oxidative stress often causes the activation of the p38/JNK pathway (28). Western blot analysis demonstrated that treatment of HT-29 cells with $5 \mu \mathrm{M}$ of SAHA caused a time-dependent increase in the levels of phosphorylated active forms of p38 and JNK, while we did not observe significant variations in the corresponding nonphosphorylated forms (Fig. 4). The level of phospho-c-Jun increased with SAHA treatment. These effects were already observed in the first phase of treatment $(8 \mathrm{~h})$ reaching the maximum at $24 \mathrm{~h}(\sim 2.5-5$-fold of the respective control values) (Fig. 4).

SAHA induced in HT-29 cells the down-regulation of $\beta$-catenin and Akt. It is well known that HT-29 cells are characterized by high levels of $B$-catenin and it has been suggested that this condition contributes to their de-regulated proliferation and resistance to apoptosis (29). Western blot analysis evidenced in these cells the presence of two bands, one which corresponds to the canonical $92 \mathrm{kDa}$ form of the protein and the other at a lower molecular weight $(\sim 70 \mathrm{kDa})$. After treatment with $5 \mu \mathrm{M}$ of SAHA for $16 \mathrm{~h}$, a decrease in the levels of the two bands with the appearance of degradation forms of the protein was observed. The effect was more evident after $24 \mathrm{~h}$ of treatment when the two bands were markedly reduced and the degradation forms became prevalent. The addition of $100 \mu \mathrm{M}$ of $\mathrm{z}-\mathrm{VAD}$ completely counteracted the effects of SAHA on B-catenin (Fig. 6, lane 4), indicating a role of caspases on $\beta$-catenin degradation.

We analysed the effect of SAHA on the serine/treonine kinase Akt, a protein which is involved in cell survival and inhibition of apoptosis (30). Western blot analysis showed that treatment with SAHA induced a reduction in Akt level. The decrease was modest after $16 \mathrm{~h}$ of treatment and became remarkable at $24 \mathrm{~h}$ (Fig. 4). In this case, the effect was reverted by the addition of z-VAD (Fig. 6).

\section{Discussion}

SAHA, a chemotherapeutic drug capable of inhibiting HDAC activity, can regulate gene expression and induce cell cycle arrest or cell death in many tumor systems (16). This study showed that colorectal carcinoma HT-29 cells express a high sensitivity to SAHA-induced apoptosis. In particular, SAHA promoted apoptosis in HT-29 cells with a dose- and timedependent mechanism, which was partially prevented by zVAD, a pan-specific inhibitor of caspase activity. Therefore, we conclude that caspases seem to be involved in the apoptotic pathway induced by SAHA.

Our results also provide evidence that SAHA induces the production of ROS in HT-29 cells. Since the antioxidant NAC prevented the cytotoxic effect of the drug, we suggest that ROS plays a crucial role in SAHA-induced apoptosis. The production of ROS was correlated with the dissipation of membrane mitochondrial potential, as suggested by the observation that NAC partially prevented the mitochondrial injury induced by SAHA. Moreover, the finding that DPI, an inhibitor frequently used to block NADPH oxidase, reduced the apoptotic effect induced by SAHA, led to the conclusion that ROS production can be dependent on NADPH oxidase activation, as recommended by many authors who correlated this activity with apoptosis (31).

Furthermore, our results revealed that the exposure of cells to SAHA stimulated the phosphorylation of p38 and JNK, two enzymes which are generally associated with ROS-dependent apoptosis. We hypothesize that the activation of p38 and JNK could be correlated with the mitochondrial membrane potential dissipation via the phosphorylation and inactivation of $\mathrm{Bcl}-2$, as demonstrated by Seo et al (32). Thus, ROS, through p38 and JNK activation could induce mitochondrial injury with the consequent activation of caspase- 9 and -3 .

However, our results also suggest a possible involvement of the extrinsic pathway in SAHA-induced apoptosis. In this connection, we observed that SAHA increased the level of the TRAIL receptor DR5 and contemporaneously diminished the level of FLIP $_{\mathrm{L}}$, an endogenous inhibitor of caspase-8, although the drug did not modify the level of the FAS receptor and that of its ligand. Therefore, the activation of the TRAIL pathway could be responsible for the activation of caspase-8, which was observed after treatment with SAHA, though it is not possible to exclude that this event was a consequence of a feedback loop related to caspase- 9 or -3 activation (33). In addition, it seems likely that the activation of caspase- 8 was responsible for the cleavage of $\mathrm{Bid}$, a pro-apoptotic factor of the Bcl-2 family, with the production of its truncated active form, which is well known in preventing the antiapoptotic action of Bcl-2 at the level of a mitochondrial membrane (34). The observation that $\mathrm{z}-\mathrm{VAD}$ partially reduced the effect of the SAHA on $\Delta \psi_{\mathrm{m}}$ dissipation supports the close relationship among the activation of caspase-8, the cleavage of Bid and the dissipation of mitochondrial potential. Therefore, mitochondrial damage induced by SAHA in HT-29 cells could be dependent on two different mechanisms: the production of ROS with the activation of p38 and JNK and the activation of caspase- 8 with cleavage of Bid.

The expression of the survival factor Akt is increased in many cancers including colorectal carcinoma (30) and may confer resistance to certain anticancer drugs. Our experiments demonstrated that the level of this protein was affected by SAHA treatment. Since Akt is responsible for antiapoptotic effects, it seems probable that its decrease can favour the induction of apoptosis in HT-29 cells. Moreover, the level of $\beta$-catenin, which contributes to the de-regulated proliferation of colorectal carcinoma, was strongly reduced after treatment with SAHA. This event, which was observed in the second phase of the treatment and was prevented by z-VAD, could be a consequence of caspase- 3 activation, as demonstrated in other cells (35).

In conclusion, our study indicates that in HT-29 cells, the main experimental model of colon carcinoma, the apoptotic mechanism induced by the inhibitor of histone deacetylase SAHA involves mitochondrial events mediated by oxidative stress and the activation of the extrinsic apoptotic pathway. Altogether, our results confirm that the drug can be considered as a promising new therapeutic strategy for human cancers.

\section{References}

1. Grunstein M: Histone acetylation in chromatin structure and transcription. Nature 389: 349-352, 1997. 
2. Carey $\mathrm{N}$ and La Thangue NB: Histone deacetylase inhibitors: gathering pace. Curr Opin Pharmacol 6: 369-375, 2006.

3. Santini V, Gozzini A and Ferrari G: Histone deacetylase inhibitors: molecular and biological activity as a premise to clinical application. Curr Drug Metab 8: 383-393, 2007.

4. Kim TY, Bang YJ and Robertson KD: Histone deacetylase inhibitors for cancer therapy. Epigenetics 1: 14-23, 2006.

5. Marks P, Rifkind RA, Richon VM, Breslow R, Miller T and Kelly WK: Histone deacetylases and cancer: causes and therapies. Nat Rev Cancer 1: 194-202, 2001.

6. Vrana JA, Decker RH, Johnson CR, Wang Z, Jarvis WD, Richon VM, Ehinger M, Fisher PB and Grant S: Induction of apoptosis in U937 human leukemia cells by suberoylanilide hydroxamic acid (SAHA) proceeds through pathways that are regulated by Bcl-2/Bcl-XL, c-Jun, and p21CIP1, but independent of p53. Oncogene 18: 7016-7025, 1999.

7. Butler LM, Agus DB, Scher HI, Higgins B, Rose A, Cordon-Cardo C, Thaler HT, Rifkind RA, Marks PA and Richon VM: Suberoylanilide hydroxamic acid, an inhibitor of histone deacetylase, suppresses the growth of prostate cancer cells in vitro and in vivo. Cancer Res 60: 5165-5170, 2000.

8. Richon VM, Sandhoff TW, Rifkind RA and Marks PA: Histone deacetylase inhibitor selectively induces p21WAF1 expression and gene-associated histone acetylation. Proc Natl Acad Sci USA 97: 10014-10019, 2000.

9. Duvic M, Talpur R, Ni X, Zhang C, Hazarika P, Kelly C, Chiao JH, Reilly JF, Ricker JL, Richon VM and Frankel SR: Phase 2 trial of oral vorinostat (suberoylanilide hydroxamic acid, SAHA) for refractory cutaneous T-cell lymphoma (CTCL). Blood 109: 31-39, 2007

10. Sonnemann J, Dreyer L, Hartwig M, Palani CD, Hong le TT, Klier U, Bröker B, Völker U and Beck JF: Histone deacetylase inhibitors induce cell death and enhance the apoptosis-inducing activity of TRAIL in Ewing's sarcoma cells. J Cancer Res Clin Oncol 133: 847-858, 2007

11. Shankar S, Singh TR, Fandy TE, Luetrakul T, Ross DD and Srivastava RK: Interactive effects of histone deacetylase inhibitors and TRAIL on apoptosis in human leukemia cells: involvement of both death receptor and mitochondrial pathways. Int J Mol Med 16: 1125-1138, 2005.

12. Marchion DC, Bicaku E, Daud AI, Richon V, Sullivan DM and Munster PN: Sequence-specific potentiation of topoisomerase II inhibitors by the histone deacetylase inhibitor suberoylanilide hydroxamic acid. J Cell Biochem 92: 223-237, 2004.

13. Kim MS, Blake M, Baek JH, Kohlhagen G, Pommier Y and Carrier F: Inhibition of histone deacetylase increases cytotoxicity to anticancer drugs targeting DNA. Cancer Res 63: 7291-7300, 2003.

14. Yu C, Rahmani M, Conrad D, Subler M, Dent P and Grant S: The proteasome inhibitor bortezomib interacts synergistically with histone deacetylase inhibitors to induce apoptosis in $\mathrm{Bcr} / \mathrm{Abl}^{+}$ cells sensitive and resistant to STI571. Blood 102: 3765-3774, 2003.

15. Emanuele S, Lauricella M, Carlisi D, Vassallo B, D'Anneo A, Di Fazio P, Vento R and Tesoriere G: SAHA induces apoptosis in hepatoma cells and synergistically interacts with the proteasome inhibitor Bortezomib. Apoptosis 12: 1327-1338, 2007.

16. Xu WS, Parmigiani RB and Marks PA: Histone deacetylase inhibitors: molecular mechanisms of action. Oncogene 26: 5541-5552, 2007

17. Kuebler JP, Wieand HS, O'Connell MJ, Smith RE, Colangelo LH, Yothers G, Petrelli NJ, Findlay MP, Seay TE, Atkins JN, Zapas JL, Goodwin JW, Fehrenbacher L, Ramanathan RK, Conley BA, Flynn PJ, Soori G, Colman LK, Levine EA, Lanier KS and Wolmark N: Oxaliplatin combined with weekly bolus fluorouracil and leucovorin as surgical adjuvant chemotherapy for stage II and III colon cancer: results from NSABP C-07. J Clin Oncol 25: 2198-2004, 2007.

18. Kwon HC, Oh SY, Lee S, Kim SH and Kim HJ: Bevacizumab plus infusional 5-fluorouracil, leucovorin and irinotecan for advanced colorectal cancer that progressed after oxaliplatin and irinotecan chemotherapy: A pilot study. World J Gastroenterol 13: 6231-6235, 2007

19. Longley DB, Allen WL and Johnston PG: Drug resistance, predictive markers and pharmacogenomics in colorectal cancer. Biochim Biophys Acta 1766: 184-196, 2006.
20. Park Y, Hunter DJ, Spiegelman D, Bergkvist L, Berrino F, van den Brandt PA, Buring JE, Colditz GA, Freudenheim JL, Fuchs CS, Giovannucci E, Goldbohm RA, Graham S, Harnack L, Hartman AM, Jacobs DR Jr, Kato I, Krogh V, Leitzmann MF, McCullough ML, Miller AB, Pietinen P, Rohan TE, Schatzkin A, Willett WC, Wolk A, Zeleniuch-Jacquotte A, Zhang SM and Smith-Warner SA: Dietary fiber intake and risk of colorectal cancer: a pooled analysis of prospective cohort studies. JAMA 294: 2849-2857, 2005.

21. Lim CC, Ferguson LR and Tannock GW: Dietary fibres as 'prebiotics': implications for colorectal cancer. Mol Nutr Food Res 49: 609-619, 2005

22. Flatmark K, Nome RV, Folkvord S, Bratland A, Rasmussen H, Ellefsen MS, Fodstad $\varnothing$ and Ree AH: Radiosensitization of colorectal carcinoma cell lines by histone deacetylase inhibition. Radiat Oncol 1: 25, 2006

23. Darzynkiewicz Z, Bruno S, Del Bino G, Gorczyca W, Hotz MA, Lassota P and Traganos F: Features of apoptotic cells measured by flow cytometry. Cytometry 13: 795-808, 1992

24. Lauricella M, Calvaruso G, Carabillò M, D'Anneo A, Giuliano M, Emanuele S, Vento R and Tesoriere G: pRb suppresses camptothecin-induced apoptosis in human osteosarcoma Saos-2 cells by inhibiting c-Jun N-terminal kinase. FEBS Lett 499 : 191-197, 2001

25. Ruefli AA, Ausserlechner MJ, Bernhard D, Sutton VR, Tainton KM, Kofler R, Smyth MJ and Johnstone RW: The histone deacetylase inhibitor and chemotherapeutic agent suberoylanilide hydroxamic acid (SAHA) induces a cell-death pathway characterized by cleavage of Bid and production of reactive oxygen species. Proc Natl Acad Sci USA 98: 10833-10838, 2001

26. Malik F, Kumar A, Bhushan S, Khan S, Bhatia A, Suri KA, Qazi GN and Singh J: Reactive oxygen species generation and mitochondrial dysfunction in the apoptotic cell death of human myeloid leukemia HL-60 cells by a dietary compound withaferin A with concomitant protection by $\mathrm{N}$-acetyl cysteine. Apoptosis 12: 2115-2133, 2007

27. Krueger A, Schmitz I, Baumann S, Krammer PH and Kirchhoff S: Cellular FLICE-inhibitory protein splice variants inhibit different steps of caspase-8 activation at the CD95 death-inducing signaling complex. J Biol Chem 276: 20633-20640, 2001.

28. Kuo PL, Chen CY and Hsu YL: Isoobtusilactone A induces cell cycle arrest and apoptosis through reactive oxygen species/ apoptosis signal-regulating kinase 1 signaling pathway in human breast cancer cells. Cancer Res 67: 7406-7420, 2007.

29. Henderson BR and Fagotto F: The ins and outs of APC and beta-catenin nuclear transport. EMBO Rep 3: 834-839, 2002.

30. Song G, Ouyang G and Bao S: The activation of Akt/PKB signaling pathway and cell survival. J Cell Mol Med 9: 59-71, 2005.

31. Wang J, Li L, Cang H, Shi G and Yi J: NADPH oxidase-derived reactive oxygen species are responsible for the high susceptibility to arsenic cytotoxicity in acute promyelocytic leukemia cells. Leuk Res 32: 429-436, 2008.

32. Seo SK, Lee HC, Woo SH, Jin HO, Yoo DH, Lee SJ, An S, Choe TB, Park MJ, Hong SI, Park IC and Rhee CH: Sulindacderived reactive oxygen species induce apoptosis of human multiple myeloma cells via p38 mitogen activated protein kinase-induced mitochondrial dysfunction. Apoptosis 12: 195-209, 2007.

33. Reddy RM, Yeow WS, Chua A, Nguyen DM, Baras A, Ziauddin MF, Shamimi-Noori SM, Maxhimer JB, Schrump DS and Nguyen DM: Rapid and profound potentiation of Apo2L/TRAIL-mediated cytotoxicity and apoptosis in thoracic cancer cells by the histone deacetylase inhibitor Trichostatin A: the essential role of the mitochondria-mediated caspase activation cascade. Apoptosis 12: 55-71, 2007

34. Baskin-Bey ES and Gores GJ: Death by association: BH3 domain-only proteins and liver injury. Am J Physiol Gastrointest Liver Physiol 289: G987-G990, 2005.

35. Rice PL, Kelloff J, Sullivan H, Driggers LJ, Beard KS, Kuwada S, Piazza G and Ahnen DJ: Sulindac metabolites induce caspase- and proteasome-dependent degradation of beta-catenin protein in human colon cancer cells. Mol Cancer Ther 2: 885-892, 2003. 